\title{
BMJ Open Association of restaurant smoking ban and the incidence of acute myocardial infarction in Finland
}

\author{
Jussi Olli Tapani Sipilä, ${ }^{1,2,3}$ Jarmo Mikael Gunn, ${ }^{4,5}$ Tommi Kauko, ${ }^{6}$ Päivi Rautava, ${ }^{7}$ \\ Ville Kytö ${ }^{4,8}$
}

To cite: Sipilä JOT, Gunn JM, Kauko T, et al. Association of restaurant smoking ban and the incidence of acute myocardial infarction in Finland. BMJ Open 2016;6: e009320. doi:10.1136/ bmjopen-2015-009320

- Prepublication history for this paper is available online. To view these files please visit the journal online (http://dx.doi.org/10.1136/ bmjopen-2015-009320).

JOTS and JMG contributed equally.

Received 6 July 2015 Accepted 19 November 2015

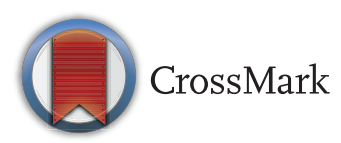

For numbered affiliations see end of article.

Correspondence to Dr Jarmo Gunn; jamigu@utu.fi

\section{ABSTRACT}

Objective: To describe the changes in nationwide acute myocardial infarction (AMI) incidence following the implementation of a law banning smoking indoors in restaurants on 1 June 2007.

Methods: Retrospective registry study of all hospitalisations for AMI in Finland. All 34887 hospitalisations for AMI between 1 June 2005 and 31 May 2009 were identified from the Care Register for Health Care (CRHC) and statistics for tobacco consumption were obtained from the National Institute for Health and Welfare. Comorbidities for individual hospitalisations were searched from the CRHC.

Results: The incidence rate of AMI was reduced by $6.3 \%(95 \% \mathrm{Cl} 4.1 \%$ to $8.6 \% ; p<0.0001)$ in the latter half of the study period following the smoking ban when adjusted for age, gender and overall population prevalence of smoking. Short-term incidence of AMI (6-month prior vs 6 months after the smoking ban) was also reduced $(4.5 \%, 95 \% \mathrm{Cl} 0.2 \%$ to $9.0 \%$; $\mathrm{p}=0.0399)$ and was largest in the working middle-aged group (40-50 years) but observed also in the oldest age group ( $>70$ years). The incidence rates declined similarly for men and women.

Conclusions: Banning indoor tobacco smoking in restaurants was associated with a mild additional reduction in $\mathrm{AMI}$ incidence on a nationwide level in Finland.

\section{INTRODUCTION}

Tobacco smoke exposure, both first-hand and environmentally, has been unequivocally linked to an increased risk of ischaemic heart disease and acute myocardial infarction $(\mathrm{AMI})^{1}$ and the effect is seen already at low exposure levels. $^{2}{ }^{3}$ Tobacco smoke increases the risk of acute cardiac events by multiple mechanisms including prothrombotic effects, low-density lipoprotein oxidation, activation of inflammatory pathways and impaired vascular repair. ${ }^{4-6}$ A previous Cochrane review suggested that indoor smoking bans have decreased the incidence of AMI on a population level via a decrease in secondhand smoking (SHS). ${ }^{7}$

\section{Strengths and limitations of this study}

- This is a study into the effects of a restaurant smoking ban on incidence of acute myocardial infarction (AMI) in a situation where working place smoking is already prohibited. A validated, obligatory national registry was used to provide reliable nationwide coverage.

- Limitations of this study include the unavailability of detailed data on tobacco smoke exposure, medication or therapies implemented. In addition, our data do not cover patients who died of an AMI prior to reaching hospital.

- The decline in AMI incidence in the oldest age groups after the implementation of the ban may be confounded by the previously reported general decline of incidence in these age groups.

Smoking in workplaces has been prohibited in Finland since 1995. This was followed by a $2-3 \%$ reduction in smoking prevalence in the following year. The ban did not initially include restaurant workers but was extended to cover them in 2000. However, since restaurant customers were still allowed to smoke indoors uninhibited, the extension was deemed insufficient to protect restaurant workers and since 1 June 2007 smoking has been prohibited indoors in all public places. Large restaurants were allowed to request for transition time until June 2009 but only 5\% of restaurants used this opportunity. Restaurants and other workplaces are allowed to build isolated, air-conditioned smoking cubicles. The aim of this study is to retrospectively assess the effects of the new legislation on the incidence of AMIs in Finland.

\section{MATERIALS AND METHODS}

We searched the Care Register for Health Care (CRHC), a nationwide obligatory and automated database maintained by the Finnish National Institute for Health and 
Welfare that contains hospital discharge diagnosis codes of all medical admissions in Finland, for patients discharged from hospital with a primary diagnosis of AMI (International Classification of Diseases, Revision 10, ICD-10 codes I21.0-49).

The study period was from 1 June 2005 up to 31 May 2009 and the search covered all University Hospitals $(\mathrm{n}=5)$ and Central Hospitals $(\mathrm{n}=17)$ in Finland (2007 population 5300484 ) along with eight of the largest district hospitals. This sample includes all Finnish hospitals that have a coronary catheterisation laboratory and a cardiac care unit and to which all acute coronary patients in scope of active treatment are transferred. Secondary diagnoses of the admission were used to identify comorbidities. Patients who had been transferred from one hospital to another were identified and are presented only once in the results.

Data were divided into two main time periods: prelegislation (from 1 July 2005 to 31 May 2007) and postlegislation (1 June 2007 to 31 May 2009). For evaluation of the immediate implications of the legislation, the period was divided into 6-month periods. Data on smoking prevalence in the general population by gender, age and year were obtained from Statistics Finland (http://www. tilastokeskus.fi), the national authority conducting continuous smoking surveillance in Finland. The smoking data are nationwide and include all age groups.

\section{Statistical methods}

Continuous variables were described in terms of mean and SD. Categorical variables were presented as frequencies and proportions (percentages). The generalised linear model was fitted using the Poisson distribution to describe the count of infarctions in terms of incidence rate ratios. The logarithmically transformed population size was used as an offset parameter. The results were adjusted for gender, age and smoking habits. All analyses were conducted using the SAS System for Windows,
V.9.4TS1M1 (SAS Institute Inc., Cary, North Carolina, USA). p Values less than 0.05 were considered as statistically significant.

\section{RESULTS}

There were 656044 hospitalisations on internal medicine wards during the study period of which 34887 were for a primary diagnosis of AMI. The mean age of patients with AMI was $68 \pm 11$ years and the majority were male $(66 \%)$. Patient features and comorbidities prior to and after 1 June 2007 are presented in table 1. A slightly larger proportion of patients with AMI were female in the first half of the study period.

The incidence rate of AMI was reduced by $6.3 \%(95 \%$ CI $4.1 \%$ to $8.6 \%$; $\mathrm{p}<0.0001$, table 2 ) in the 2 years following the smoking ban when compared to the prelegislation period and adjusted for age, gender and overall population prevalence of smoking (figure 1). Short-term reduction in incidence of AMI was observed already in the 6 months following the ban $(4.5 \%$ compared to the preceding 6 months, 95\% CI $0.2 \%$ to $9.0 \%$; $\mathrm{p}=0.0399$, figure 2), and was most prominent in the working middle-aged group ( $40-50$ years) but observed also in the oldest age group of those over 70 years.

Increasing age and male gender were associated with increased risk for AMI (table 2). Furthermore, agespecific and gender-specific smoking prevalence in the general population (figure 3) was also associated with occurrence of AMI (table 2). AMI presented with ST-segment elevation (STEMI) in 37\% $(n=12923)$ of patients. The ratio between STEMI and non-STEMI (NSTEMI) did not change over the study period.

\section{DISCUSSION}

This study associates a nationwide ban on indoor tobacco smoking in public places with an immediate $4.5 \%$ reduction and a longer term $6.3 \%$ reduction in

Table 1 Comorbidities and characteristics of patients hospitalised between June 2005 and May 2009 for acute myocardial infarctions in Finland before and after the law banning indoor smoking in restaurants since June 2007

\begin{tabular}{lllr}
\hline Variable & $\begin{array}{l}\text { Before June 2007 } \\
(\mathbf{n = 1 8 ~ 4 8 7 )}\end{array}$ & $\begin{array}{l}\text { After June 2007 } \\
\text { (n=16 400) }\end{array}$ & p Value \\
\hline Age & $68.5 \pm 11.4$ & $68.3 \pm 11.3$ & 0.187 \\
Female gender & $6491(35.1 \%)$ & $5453(33.3 \%)$ & $2615(15.9 \%)$ \\
Hypertension & $2869(15.5 \%)$ & $1464(8.9 \%)$ & 0.275 \\
Diabetes & $1630(8.8 \%)$ & $1364(8.3 \%)$ & 0.719 \\
Hypercholesterolaemia & $1435(7.8 \%)$ & $1770(10.8 \%)$ & 0.057 \\
Congestive heart failure & $1985(10.7 \%)$ & $969(5.9 \%)$ & 0.868 \\
Atrial fibrillation & $1085(5.9 \%)$ & $150(0.9 \%)$ & 0.876 \\
Peripheral arterial disease & $145(0.8 \%)$ & $357(2.2 \%)$ & 0.185 \\
Chronic lung disease & $447(2.4 \%)$ & $154(0.9 \%)$ & 0.134 \\
Chronic kidney disease & $157(0.8 \%)$ & $169(1.0 \%)$ & 0.373 \\
Malignancy & $191(1.0 \%)$ & $553(3.4 \%)$ & 0.980 \\
Prior revascularisation & $666(3.6 \%)$ & $80(0.5 \%)$ & 0.242 \\
Rheumatoid arthritis & $102(0.6 \%)$ & $52(0.3 \%)$ & 0.408 \\
Thyroid disease & $46(0.2 \%)$ & & 0.229 \\
\hline
\end{tabular}


Table 2 Factors associated with AMI incidence in Finland between June 2005 and May 2009

\begin{tabular}{|c|c|c|c|}
\hline Variable & IRR & $95 \% \mathrm{Cl}$ & p Value \\
\hline Age (per year) & 1.050 & 1.048 to 1.051 & $<0.0001$ \\
\hline Male gender & 1.578 & 1.536 to 1.621 & $<0.0001$ \\
\hline $\begin{array}{l}\text { Period before } \\
1 \text { June } 2007^{\star}\end{array}$ & 1.063 & 1.041 to 1.086 & $<0.0001$ \\
\hline $\begin{array}{l}\text { Higher smoking } \\
\text { prevalence per \%† }\end{array}$ & 1.031 & 1.028 to 1.034 & $<0.0001$ \\
\hline
\end{tabular}

the incidence rate of AMIs on a population level in Finland. The reduction of AMI rate was most notable in the working-age population aged 40-50 years but observed also in people $>70$ years of age. No difference in rate reduction between genders was found and nor did the ratio of STEMI to NSTEMI change.

A previous meta-analysis of studies on the effect of indoor smoking bans showed an average reduction of $17 \%$ in AMI incidence with individual studies ranging between a non-significant increase and a $50 \%$ reduction. $^{7-13}$ The current study demonstrated only a $4.5 \%$ reduction in AMI incidence when comparing the first and latter halves of the year 2007 and a $6.3 \%$ reduction on a longer time scale. The most obvious reason for the modest reduction in our study is that there are differences in smoking bans: for example, in Italy the ban was implemented in all working places, whereas in Finland smoking in other workplaces than restaurants had been banned since 1995, making the target population in the present study considerably smaller. Moreover, the declining smoking prevalence in Finland was associated with reductions in AMI incidence in this study, although the countries represented in the meta-analysis by Meyers

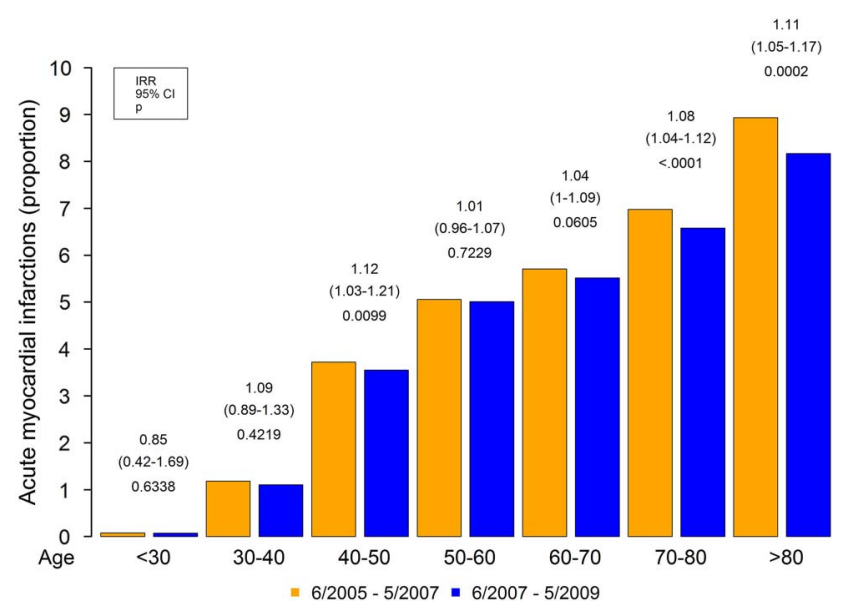

Figure 1 Incidence of hospitalisation for acute myocardial infarction in Finland. 1 June 2007 was the date of implementation of a nationwide restaurant smoking ban.

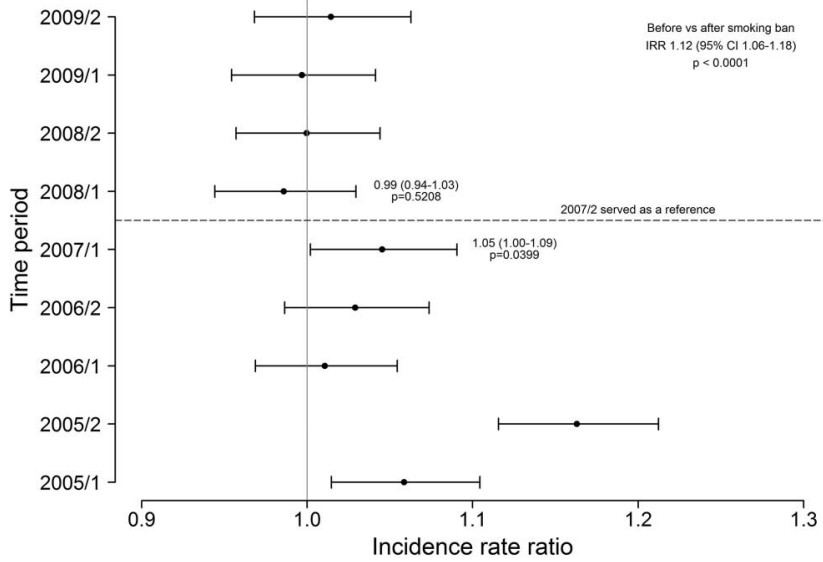

Figure 2 Incidence rate ratios of acute myocardial infarction for 6-month intervals in Finland. Dotted line indicates implementation of a new law banning smoking in restaurants. 1 indicates the first half of the year and 2 the latter half $(\mathrm{eg}$, 2009/1 and 2009/2).

and colleagues had similar and declining smoking prevalences of 24-29\% before implementation of the bans. It should be noted that, despite significant improvement attributable to nationwide public health measures in the past decades, Finland has an almost twofold AMI incidence compared to the countries describing reduced AMI incidence following indoor smoking bans. ${ }^{14}$ Thus, the absence of a more pronounced effect cannot be attributed to the low rate of vascular events in the population. On the other hand, in comparison with many other countries, the proportion of STEMI as the form of AMI has steadily increased in Finland. ${ }^{15-18}$ The reason for this is unknown, but considering the pathophysiological differences of STEMI and NSTEMI, ${ }^{19}$ one could suppose that population-specific factors might result in differences between clinical outcomes of smoking bans in different countries. However, our results showed no change in the ratio of STEMI versus NSTEMI over the study period.

The reduction in AMI incidence following the ban was greatest in the age group 40-50 years, which includes restaurant patrons and a large proportion of the approximately 43000 persons who were classified as restaurant staff in 2008 (data obtained from the Finnish Ministry of Education). It is conceivable that the new legislation could have deterred smoking in a number of active smokers among this populace and thus further reduced first-hand and environmental exposure to tobacco smoke both inside and outside restaurants. The fact that tobacco smoking prevalence decreased markedly in persons aged 25-60 years between 2007 and 2008 (Finnish National Institute for Health and Welfare Tobacco Statistics 2014) lends support to the aforementioned hypothesis. ${ }^{20}$ This could also explain why there was no reduction in AMI incidence in the age group 60-70 years as their smoking prevalence rather showed an increase. Furthermore, the decline in smoking prevalence was greater in those aged $40-50$ years compared to 


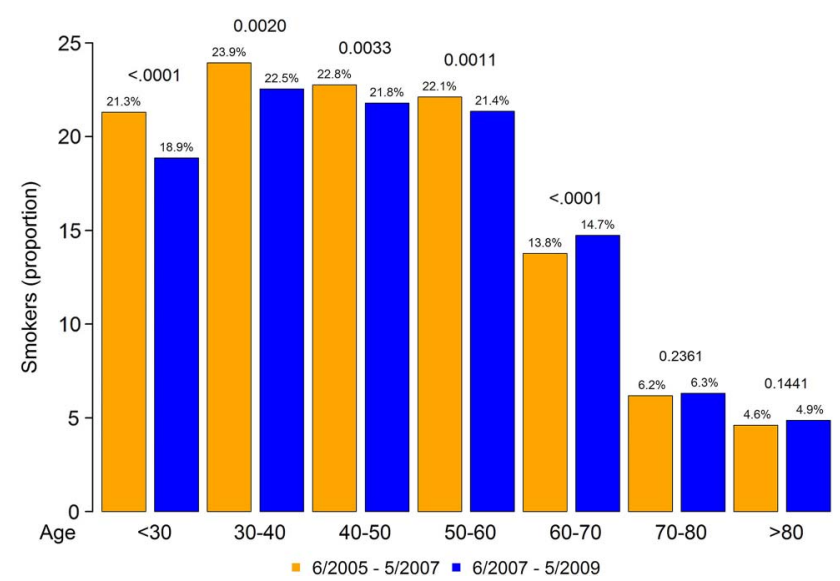

Figure 3 The proportion of smokers according to age group in the Finnish population in the preban (from 1 June 2005 to 31 May 2007) and postban (1 June 2007 to 31 May 2009) study periods.

those aged 50-60 years. Additionally, we do not have data as to when exactly during the study period the decline has taken place, and possible differences in the temporal pattern of quitting smoking could explain the differences. Even greater declines in smoking prevalence were observed in the population aged below 40 years, but the marginal incidence of AMI in these age groups probably explains the lack of effect on AMI incidence. Non-smoking rapidly halves the risk of myocardial infarction. ${ }^{21}$ In 2007, an environmental tobacco smoke exposure of over $4 \mathrm{~h}$ per shift occurred for $37 \%$ of restaurant waiters and $67 \%$ of bartenders and about $28 \%$ of restaurant workers were active smokers. ${ }^{22}$ Previous studies have already shown that the 2007 ban was effective in reducing environmental exposure and, consequently, symptoms in restaurant workers. ${ }^{23}$ This reduction in occupational exposure alone should translate into some hundreds of AMIs less per year such as have been shown in the results of this study.

Interestingly, the oldest age group (70 years and over) showed reduced rates of AMI following the ban in our study. Since people of this age do not frequent restaurants and bars and showed no decline in smoking prevalence following the ban, it seems there must be some other explanation for their reduced risk. Indeed, earlier studies have shown that up to $67 \%$ of the reduction in AMI incidence after smoking bans may be accounted for by non-smokers ${ }^{13}$ and these effects may be conveyed by the decreased smoking of carers and relatives in the case of the elderly. Considering that the risk of AMI rises with age ${ }^{24}$ it seems probable that elderly people are also more sensitive to external AMI triggers than younger ones. Nevertheless, the decline in AMI incidence in European populations over the past decades has been shown to be more pronounced in the age group of 6574 years compared to those aged $35-64$ years $^{25}$ and this may confound the results of the elderly. However, the fact that we found no change in the AMI risk of those aged $60-70$ years decreases the likelihood this development has affected our results decisively.

Limitations of this study are those inherent to a retrospective registry study; that is, all confounders cannot be accounted for particularly as the study group had no access to individual patient records but only the information contained in the CRHC, which, however, has been validated for patients with AMI. ${ }^{26}$ Since our data consisted only of those patients with AMI who were admitted, those who died prior to hospitalisation were not included. Whereas other studies that have shown a negligible effect of indoor smoking bans on AMI incidence have speculated that the modest effect might have been due to short follow-up periods, ${ }^{82} 28$ this study had an extensive observation period and our results are comparable in the short and long terms, adding to the strength of our study. However, even as the association of the smoking ban with a reduction in the AMI rate is evident in this study, the prolonged effects are harder to discern, especially as there was a nationwide public health project from 2000 to 2010 aimed at improving outcomes of diabetes; this project has no doubt affected AMI rates in addition to other outcomes. ${ }^{29}$ Lastly, the effect of environmental tobacco smoke exposure on the risk of cardiovascular disease is dependent on the dose and duration of exposure. ${ }^{4}$ Our ecological study design does not allow us to account for these factors, so our interpretation focuses on the population level. We found the incidence of AMI diagnoses to decrease in the first half of 2006 compared to 2005. Although reasons for this remain speculative, it may be related to the transition phase in the more widespread use of non-high sensitivity troponin assays in AMI diagnosis.

\section{CONCLUSIONS}

Legislative measures stopping indoor smoking in restaurants and other public spaces coincided with an incremental reduction in the incidence of AMIs on a national level in Finland. These results suggest that in a country with an already implemented prohibitive legislation on workplace smoking, the incidence of AMI can still be modestly reduced with a ban on restaurant smoking. However, factors associated with the continual decline of AMI incidence may also explain this finding to some extent.

\section{Author affiliations}

${ }^{1}$ Division of Clinical Neurosciences, Turku University Hospital, Turku, Finland

${ }^{2}$ Department of Neurology, University of Turku, Turku, Finland

${ }^{3}$ Neurology Clinic, North Karelia Central Hospital, Joensuu, Finland

${ }^{4}$ Heart Center, Turku University Hospital, Turku, Finland

${ }^{5}$ Department of Surgery, Faculty of Medicine, University of Turku, Turku,

Finland

${ }^{6}$ Department of Biostatistics, Faculty of Medicine, University of Turku, Turku, Finland

${ }^{7}$ Department of Public Health, Faculty of Medicine, University of Turku, Turku, Finland

${ }^{8}$ Research Centre of Applied and Preventive Cardiovascular Medicine, University of Turku, Turku, Finland 
Contributors JMG prepared and submitted the manuscript which all other authors had commented on and helped revise. JOTS, PR and VK planned the study. TK and JMG analysed the data. TK prepared the figures. JOTS prepared the revisions which all other authors commented on.

Funding This research received no specific grant from any funding agency in the public, commercial or not-for-profit sectors.

Competing interests None declared.

Ethics approval Approved by the Finnish National Institute for Health and Welfare.

Provenance and peer review Not commissioned; externally peer reviewed.

Data sharing statement No additional data are available.

Open Access This is an Open Access article distributed in accordance with the Creative Commons Attribution Non Commercial (CC BY-NC 4.0) license, which permits others to distribute, remix, adapt, build upon this work noncommercially, and license their derivative works on different terms, provided the original work is properly cited and the use is non-commercial. See: http:// creativecommons.org/licenses/by-nc/4.0/

\section{REFERENCES}

1. Iversen B, Jacobsen BK, Løchen ML. Active and passive smoking and the risk of myocardial infarction in 24,968 men and women during 11 year of follow-up: the Tromsø Study. Eur J Epidemiol 2013;28:659-67.

2. Law MR, Wald NJ. Environmental tobacco smoke and ischemic heart disease. Prog Cardiovasc Dis 2003;46:31-8.

3. Khawaja O, Al-Mallah M. The impact of public smoking ban on the incidence of myocardial infarction hospitalizations. Rev Cardiovasc Med 2010 Summer;11:e121-9.

4. Benowitz NL. Cigarette smoking and cardiovascular disease: pathophysiology and implications for treatment. Prog Cardiovasc Dis 2003;46:91-111.

5. Jalkanen J, Yegutkin GG, Hollmén M, et al. Aberrant circulating levels of purinergic signaling markers are associated with several key aspects of peripheral atherosclerosis and thrombosis. Circ Res 2015;116:1206-15

6. Dunbar A, Gotsis W, Frishman W. Second-hand tobacco smoke and cardiovascular disease risk: an epidemiological review. Cardiol Rev 2013;21:94-100.

7. Callinan JE, Clarke A, Doherty $\mathrm{K}$, et al. Legislative smoking bans for reducing secondhand smoke exposure, smoking prevalence and tobacco consumption. Cochrane Database Syst Rev 2010;(4): CD005992.

8. Meyers DG, Neuberger JS, He J. Cardiovascular effect of bans on smoking in public places: a systematic review and meta-analysis. J Am Coll Cardiol 2009:54:1249-55.

9. Sargent RP, Shepard RM, Glantz SA. Reduced incidence of admissions for myocardial infarction associated with public smoking ban: before and after study. BMJ 2004;328:977-80.

10. Liu A, Guzman Castillo M, Capewell S, et al. Reduction in myocardial infarction admissions in Liverpool after the smoking ban: potential socioeconomic implications for policymaking. BMJ Open 2013;3:e003307.
11. Agüero F, Dégano IR, Subirana I, et al. Impact of a partia smoke-free legislation on myocardial infarction incidence, mortality and case-fatality in a population-based registry: the REGICOR study. PLOS ONE 2013;8:e53722.

12. Sargent JD, Demidenko E, Malenka DJ, et al. Smoking restrictions and hospitalizations for acute coronary events in Germany. Clin Res Cardiol 2012;101:227-35.

13. Pell JP, Haw S, Cobbe S, et al. Smoke-free legislation and hospitalizations for acute coronary syndrome. N Engl J Med 2008;359:482-91.

14. Havulinna AS, Pääkkönen R, Karvonen M, et al. Geographic patterns of incidence of ischemic stroke and acute myocardial infarction in Finland during 1991-2003. Ann Epidemiol 2008;18:206-13.

15. Kytö V, Sipilä J, Rautava P. Likelihood and predictors of ST-elevation in patients hospitalized for myocardial infarction. PLoS ONE 2014;9:e108440.

16. Yeh RW, Sidney S, Chandra M, et al. Population trends in the incidence and outcomes of acute myocardial infarction. $N$ Engl $J$ Med 2010;362:2155-216

17. Jennings SM, Bennett $\mathrm{K}$, Lonergan $\mathrm{M}$, et al. Trends in hospitalisation for acute myocardial infarction in Ireland, 1997-2008. Heart 2012;98:1285-9.

18. André $\mathrm{R}$, Bongard $\mathrm{V}$, Elosua $\mathrm{R}$, et al. International differences in acute coronary syndrome patients' baseline characteristics, clinical management and outcomes in Western Europe: the EURHOBOP study. Heart 2014;100:1201-7.

19. Santos-Gallego CG, Picatoste B, Badimón JJ. Pathophysiology of acute coronary syndrome. Curr Atheroscler Rep 2014;16:401.

20. Finnish National Institute for Health and Welfare. http://www.thl.fi. (accessed 16 Nov 2015).

21. Lightwood JM, Glantz SA. Short-term economic and health benefits of smoking cessation: myocardial infarction and stroke. Circulation 1997;96:1089-96.

22. Reijula JP, Reijula KE. The impact of Finnish tobacco legislation on restaurant workers' exposure to tobacco smoke at work. Scand Public Health 2010;38:724-30.

23. Reijula JP, Johnsson TS, Kaleva PS, et al. Exposure to tobacco smoke and prevalence of symptoms decreased among Finnish restaurant workers after the smoke-free law. Am J Ind Med 2012;55:37-43.

24. Kytö V, Sipilä J, Rautava P. Association of age and gender with risk for non-ST-elevation myocardial infarction. Eur J Prev Cardio 2015;22:1003-8.

25. Dégano IR, Salomaa V, Veronesi G, et al. Twenty-five-year trends in myocardial infarction attack and mortality rates, and case-fatality, in six European populations. Heart 2015;101:1413-21

26. Pajunen $\mathrm{P}$, Koukkunen $\mathrm{H}$, Ketonen $\mathrm{M}$, et al. The validity of the Finnish Hospital Discharge Register and Causes of Death Register data on coronary heart disease. Eur J Cardiovasc Prev Rehabil 2005;12:132-7.

27. Cesaroni G, Forastiere F, Agabita N, et al. Effect of the Italian smoking ban on population rates of acute coronary events. Circulation 2008;117:1183-8.

28. Vaselli B, Papini P, Gaelone D, et al. Reduction incidence of myocardial infarction associated with a national legislative ban on smoking. Minerva Cardioangiol 2008;56:197-203.

29. Lindström J, Absetz P, Hemiö K, et al. Reducing the risk of type 2 diabetes with nutrition and physical activity-efficacy and implementation of lifestyle interventions in Finland. Public Health Nutr 2010;13:993-9. 